\title{
Immediate management of rotated young permanent incisor by surgical approach - A case report
}

\author{
Rashmi K.B ${ }^{1, *}$, Kannan Vadakkepurayil ${ }^{2}$ \\ ${ }^{1}$ Junior Resident, ${ }^{2}$ Professor and HOD, Dept. of Pedodontics, Government Dental College, Kozhikode, Kerala, India
}

*Corresponding Author: Rashmi K.B

Email: drrashmisunil2001@gmail.com

\begin{abstract}
Tooth rotation is displacement of tooth around its long axis. Fixed and removable orthodontics are the conventional methods for management of rotation. But in case of single tooth rotation especially for teeth with single conical root with open apex another option is surgical approach. The procedure is called surgical derotation. It is the repositioning of a rotated tooth in normal alignment along with adjacent tooth in the dental arch, by surgical method. The procedure is simple and gives patient aesthetic result immediately without relapse. This is a case report of successful management of almost 120 degree mesiopalatally rotated maxillary right central incisor with open apex of a 9 year old girl.
\end{abstract}

Keywords: Tooth rotation, Derotation, Splint, Maxillary central incisor, Young permanent tooth.

\section{Introduction}

Tooth rotation is defined as noticeable mesiolingual or distolingual intra-alveolar displacement of a tooth around its longitudinal axis. ${ }^{1}$ It is common in premolar-molar region, but rotation of the maxillary central incisor, especially single tooth rotation is rare. Etiology can be considered to be multifactorial. Both local and genetic factors mainly contribute this positional anomaly. ${ }^{2}$

Gupta et al classified the tooth rotation into three groups -group I: $\left\langle 45^{\circ}\right.$; group II: $45^{\circ}$ to $90^{\circ}$; group III: $>90^{\circ}$. Common rotations are found in between $45^{\circ}$ and $90^{\circ}$, followed by $<45^{\circ}$ of rotations and $>90^{\circ}$ categories. ${ }^{2}$ In which 90 to 180 degree rotations can be considered as severe and it is very rare. The most common tooth rotation is seen in mandibular second premolar, then mandibular first premolar and maxillary central incisor respectively. Compared to males, females show more predilection.

Management of rotated incisor by orthodontic method is well accepted method following today. The most common disadvantage of orthodontic derotation, is, relapse after treatment. ${ }^{3}$ This can be managed by Circumferential supracrestal fibrotomy or pericision, long-term retention with bonded retainers or by overcorrection of the defect. ${ }^{4}$ But the successful prevention of rotational relapse is not completely satisfied by all these methods. ${ }^{5}$ Long duration of the treatment is also not accepted by all patients. And in cases with severe rotation (group III), a complex derotation techniques, as well as good patient cooperation is required. ${ }^{4}$

Another option of rotated tooth management is by a minor surgical procedure which is done under local anaesthesia. This procedure is known as surgical derotation or intentional derotation. This procedure gives patient aesthetic result immediately, and there is no relapse following treatment. Here the derotated tooth is first luxated using forceps by giving mild rotational movements, both clockwise and anticlockwise and positioned into the correct alignment without giving any extrusional force. The tooth should be stabilized for 2 to 3 weeks. This procedure gives patient aesthetic result immediately, and there is no relapse following treatment. But all teeth are not good candidates for this procedure. Teeth with single conical root (mostly maxillary incisors and mandibular premolars)are ideal because that can be easily rotated within the socket without breakage and it will be fit to the socket and no modifications of the socket required. ${ }^{4}$ Second factor affecting the outcome of surgical derotation is root development. Immature permanent tooth (Nolla's Stage $7 \& 8)$ is considered to be ideal, in which there is chances of revascularization and so that tooth vitality is maintained. ${ }^{6}$ In cases of tooth with closed apex, there is chances for the tooth to become non vital. And of course patient and parent cooperation is also a main factor for the success of surgical derotation procedure.

This article presents surgical management of a 9 year old girl's maxillary right central incisor which was almost 120 degree rotated mesiopalatally. The case is under follow up for a period of last 6 months with clinical and radiographic success.

\section{Case Report}

A nine year old girl, Ayisha Husna with her mother reported to our department, the Department of Pedodontics and Preventive Dentistry, Govt. Dental College, Kozhikode, Kerala. Their chief complaint was irregularly erupted upper front tooth. On clinical examination, patient was in mixed dentition period with all 1st permanent molars, lower permanent incisors and upper central incisors are erupted. Her maxillary right central incisor was almost 120 degree mesiopalatally rotated (Fig. 1A) (Fig. 1B). Intraoral periapical radiograph revealed incomplete development of root of both 11 and 21(Nolla's stage 7) (Fig. 1C). She had a history of cleft lip and cleft alveolus which was 
corrected at 2 years of age. Panoramic radiograph showed congenital absence of upper right and left lateral incisors and there was no supernumerary tooth associated with rotated tooth. The patient and parents needed an immediate result, so we planned for surgical derotation.

After making a diagnostic cast, the space available for derotation of tooth was calculated. Then the rotated incisor in the cast was trimmed and made a wax pattern of incisor with normal alignment and prepared an occlusal splint with acrylic.

Treatment procedure was explained to the parents. The advantages and disadvantages of the treatment along with its possible postoperative complications described and a written informed consent was taken. ${ }^{4}$ After applying topical agent, local infiltration anaesthesia given. A root forceps was engaged on mesial and distal surfaces of the rotated tooth with proper support of the tooth with gauze; it was luxated gently by giving rotational movements without applying any extrusional force. ${ }^{4}$ Once the tooth was luxated, it was derotated anticlockwise to its aligned position, pressed it firmly into the socket that is apically. Then splint was cemented and kept for 2 weeks (Fig. 2). Patient was discharged. Prescribed mild analgesics for two days. Advised soft diet for two weeks and gave proper oral hygiene instructions.

Splint was removed after 2 weeks and the tooth was normal and stable. (Fig. 3A) Advised soft diet for 1 more week. Periapical radiograph showed normal physiological root development along with adjacent tooth with no signs of infection or root resorption (Fig. 3B). Derotated tooth (11) clinically evaluated. No change in colour and abnormal mobility was detected. Percussion sound and pulp vitality tests were normal. All clinical and radiographic parameters recorded during follow ups were normal. Patient is under follow up for last 6 months. We had maintained some observation period for further prosthodontic replacement of missing lateral incisors.

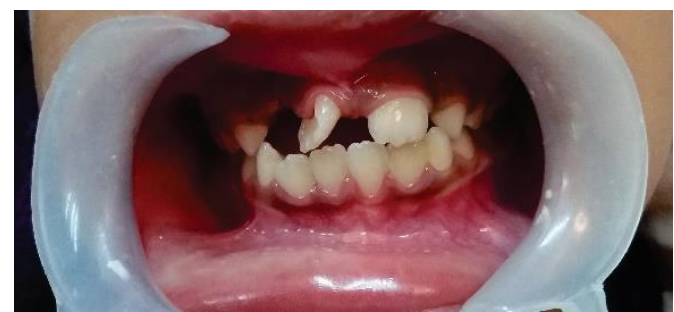

Fig. 1A

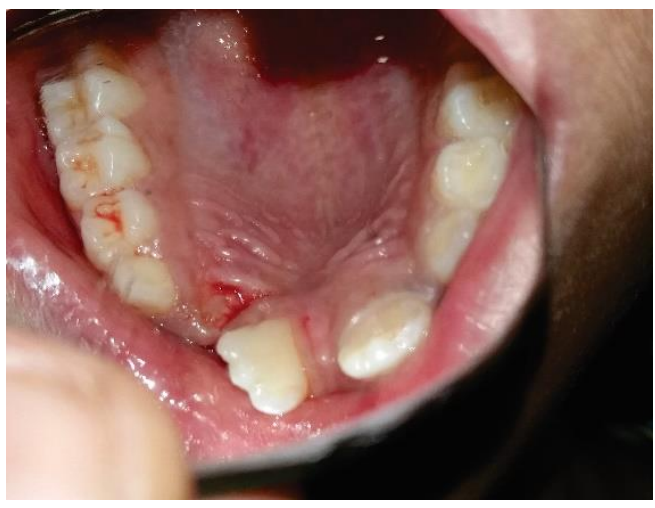

Fig. 1B

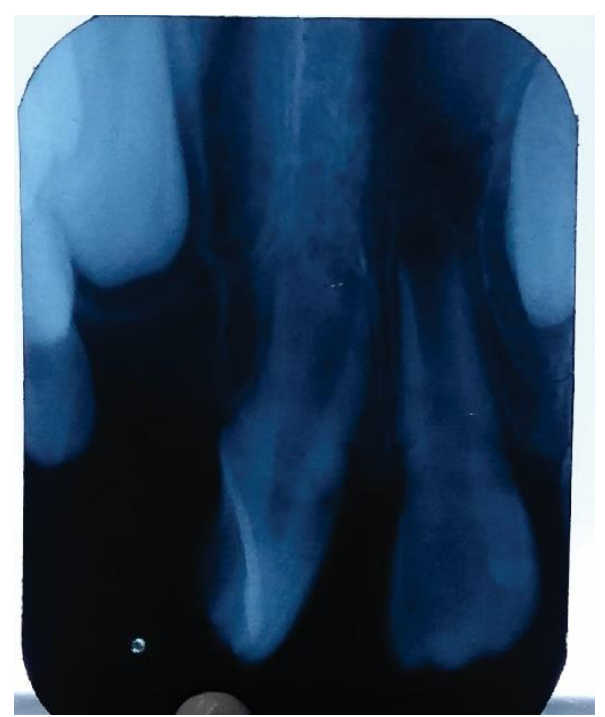

Fig. 1C

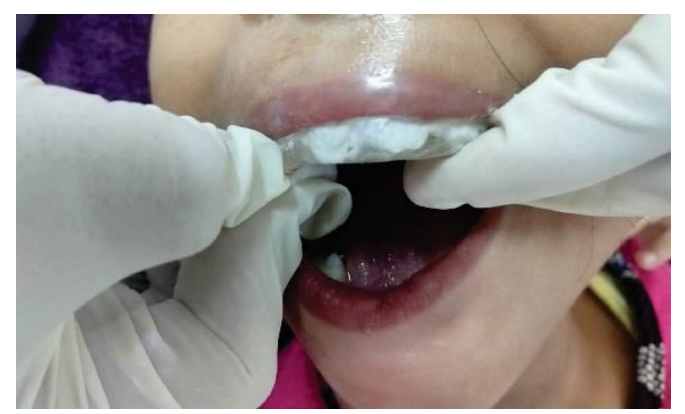

Fig. 2

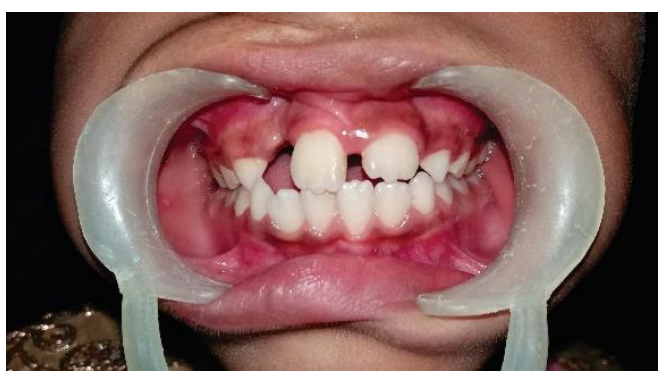

Fig. 3A 


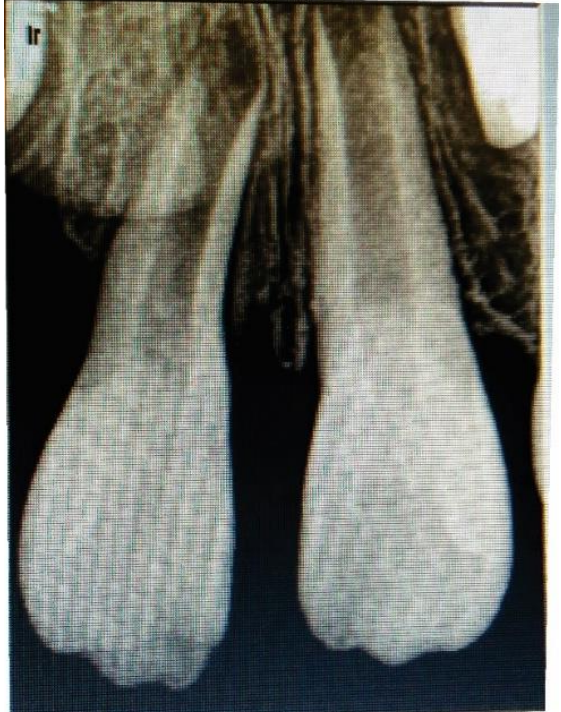

Fig. 3B

\section{Discussion}

Surgical derotation is not considered as a traditional method for correction of rotated tooth because of lack of more studies and follow ups. ${ }^{4}$ Conventional treatment is orthodontic derotation by removable and fixed appliance. But in this case fixed appliance therapy was not considered ideal because root formation was not completed and removable appliance may not give desired result with short duration. ${ }^{7}$

This technique is cost-effective and simple compared to routine orthodontic derotation procedure. But the most important advantages are immediate aesthetic improvement without relapse. ${ }^{4}$ When tooth get derotated, all gingival fibres and periodontal fibres get detached from the root. Within 2 to 3 weeks all fibres get reorganized in the new position. ${ }^{8}$ In cases of tooth with closed apex, when derotated forcefully, blood vessels and nerve fibres entering through the foramen get injured with derotation, and there is no chances of regeneration and that will leads to pulp necrosis. However, tooth with open apex, there is chances for the revascularization and regeneration of nerve fibres and that will lead to normal physiological growth and vitality. ${ }^{9}, 10$

Degree of rotation as well as space availability for the alignment should be calculated before the procedure. And if there is lack of space, space creation is necessary using removable appliance. This case was an ideal candidate for the procedure because the tooth was rotated by almost $120^{\circ}$ and was with open apex. There was sufficient space to accommodate M-D width of the crown. Clinically and radiographically this case is found to be very success along with patient and parent satisfaction.

\section{Conclusion}

Tooth derotation by surgical approach can be considered as an excellent treatment option for rotated tooth, especially for maxillary central incisor. But ideal case selection, proper surgical approach and patient and parent cooperation are necessary for good results. But we need more studies with long term successful follow ups for this method to be recommended as a viable option.

\section{References}

1. Bayani S1 KS. Correction of a severely rotated maxillary central incisor with the Whip device. Int J Orthod Milwaukee. PMID: 2236.

2. Report C. Esthetic Correction of Rotated Maxillary Central Incisor by Conservative Approach. 2016;7(December):217-20.

3. Naraghi S, Andrén A, Kjellberg H, Mohlin BO. Relapse tendency after orthodontic correction of upper front teeth retained with a bonded retainer. Angle Orthod. 2006;76(4):570-6.

4. Dutta B, Krishnapriya V, Sriram CH, Reddy MK. Surgical Derotation Technique: A Novel Approach in the Management of Rotated Immature Permanent Incisor. Int J Clin Pediatr Dent. [Internet]. 2015;8(3):220-3.

5. Mette. A.R, Kuijpers, Starvos Kiliaridis A. Anterior tooth wear and retention type until 5 years after orthodontic treatment. Acta Odontol Scand. 67;(3):176-181.

6. Andreasen FM, Zhijie Y TB. Relationship between pulp dimensions and development of pulp necrosis after luxation injuries in the permanent dentition. Endod Dent Traumatol. PMID: 3460.

7. Madhav VN. of Dental Sciences. Indian J Dent Sci. 2012;4(4):123-6.

8. Pohl Y, Filippi A, Tekin U KH. Periodontal healing after intentional auto-alloplastic reimplantation of injured immature upper front teeth. J Clin Periodontol. 2000;27(3):198-204.

9. Lee R, Barrett EJ, Kenny DJ. Clinical outcomes for permanent incisor luxations in a pediatric population. II. Extrusions. Dent Traumatol. 2003;19(5):274-9.

10. Andreasen FM PB. Prognosis of luxated permanent teeththe development of pulp necrosis. Endod Dent Traumatol. 1(6):207-20. 